\title{
Echoes of time in images of the Antarctic
}

\section{British landscape artist Chris Drury imaginatively interprets radar pictures taken of ancient ice layers underneath the south pole.}

\section{Martin Kemp}

We have become accustomed to the idea that, in nature, time frequently manifests itself in layers. We may think of the rings in trees or the ridges in shells, both formed by patterns of unequal growth. Over

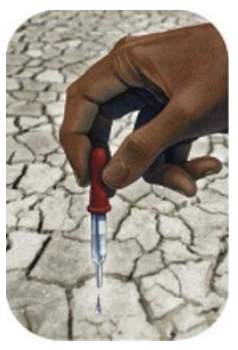

four kilometres deep and 900,000 years old. The echogram data Drury used - the printouts of which can be as long as 20 metres - resulted from four-hour round flights over the polar landscape. Fascinated both by the images themselves and their resonances with other physical phenomena, he printed \begin{abstract}
time.
With our present urgent concern
what we are doing to our planet, the
that are locked into the succession of l
rock have become more than a simple
\end{abstract} rock have become more than a simple
of understanding the deep history of E time. As with much good history, these have the potential to help us make inforn judgements about the future.

This is particularly true of the pattern ice and snow accumulation in polar regi where the single element of frozen displays, in the most direct way, the regul ties and irregularities of temperatureprocesses within the body of Earth.

In December 2006, the British artist Drury travelled to Antarctica to wor the British Antarctic Survey for three as part of its artists and writers program Drury has developed a habit of discern the analogous nature of organic and ganic phenomena across different scal Antarctica he discovered an awesome that did not readily yield to his estab practices.

"The ice sheets of Antarctica are an less expanse of nothingness," he writes. the kind of intense nothingness that bo and empties the mind." In the face of th lime vastness, "any mark made by man pissing in the wind - irrelevant and gon the next moment".

He began his time in Antarctica by sculptural interventions in the physica ronment, but became increasingly en with the methods that the scientist using to chart the expanse of time emb ded within the thick slabs of ice beneat feet.

One such method uses ice-penet radar beamed from an aircraft to obt echograms from ice strata that are
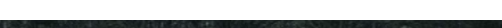
The data in the original echograms are way. As an artist, Drury hopes to draw us 